\title{
EFEITOS DE HERBICIDAS NOS TEORES DE CLOROFILAS DE Spirodela punctata ${ }^{1,2}$
}

\author{
DURVALINA M. M. DOS SANTOS ${ }^{3}$, ROBINSON A. PITELLI ${ }^{4}$ e DAVID A. BANZATTO ${ }^{5}$
}

\section{RESUMO}

Com o objetivo de verificar na planta aquática Spirodela punctata o efeito de diferentes concentrações $\left(0,005 ; 0,05 ; 0,5\right.$ e $5 \mathrm{mgL}^{-1}$ de ingrediente ativo) dos herbicidas butachlor, glyphosate e propanil sobre os teores de clorofila $\mathbf{a}, \mathbf{b}$ e na razão clorofila $\mathbf{a} / \mathbf{b}$, foram conduzidos, por sete dias completos, bioensaios em sala climatizada. Determinou-se os teores de clorofilas através de leituras espectrofotométricas nas absorbâncias $\quad \mathrm{A}_{645} \quad$ e $\quad \mathrm{A}_{663} \quad \mathrm{~nm}$. Os resultados mostraram que o butachlor diminuiu o teor de clorofila b, o glyphosate o teor de clorofila a, enquanto o propanil diminuiu os teores de clorofila $\mathbf{a}, \mathbf{b}$ e a razão $\mathbf{a} / \mathbf{b}$, provocando a maior redução de pigmentos na espécie.

Palavras chave: Pigmentos, butachlor, propanil, glyphosate, planta aquática.

\section{Effect of the herbicides on the chlorophyll content of Spirodela punctata}

The aim of this study was to verify the effects of the herbicides butachlor, glyphosate and propanil on content of chlorophyll of aquatic plant Spirodela punctata. In order to determine the effect of different concentrations of 0.005 ; 0.05 ; 0.5 and $5 \mathrm{mgL}^{-1}$ (active ingredient) of three herbicides on the contents of chlorophyll $\mathbf{a}, \mathbf{b}$ and $\mathbf{a} / \mathbf{b}$ ratio. The bioassays were conducted, for a period of seven full days, in a climated- controlled room. Chlorophyll content was determined by spectrophotometric absorbency readings at $A_{645}$ and $A_{663} \mathrm{~nm}$. Butachlor reduced chlorophyll $\mathbf{b}$, the glyphosate decrease chlorophyll $\mathbf{a}$, while the propanil reduced chlorophyll $\mathbf{a}, \mathbf{b}$ and $\mathbf{a} / \mathbf{b}$ ratio, causing the greatest reduction of the pigments in the species.

Key words: Pigments, butachlor, propanil, glyphosate, aquatic plant.

\section{INTRODUÇÃO}

A biossíntese da clorofila e o desenvolvimento dos cloroplastos podem ser inibidos por herbicidas que interferem em estruturas dos cloroplastos maturos, conduzindo à perda deste pigmento (Wolf, 1977). Estes compostos podem, além da interferência na síntese de clorofila, também, afetar a formação de outros pigmentos (Anderson \& Robertson, 1960; Sandmann \& Boger, 1987).

Os herbicidas butachlor, glyphosate e propanil são freqüentemente utilizados em ambientes aquáticos visando ao controle químico de muitas espécies daninhas, destacando-se, principalmente, a utilização do butachlor e

\footnotetext{
${ }^{1}$ Recebido para publicação em 29/01/97 e na forma revisada em 21/09/99.

${ }^{2}$ Parte da tese do primeiro autor apresentada para obtenção do título de Doutor.

${ }^{3}$ Prof. Assistente Dr., Departamento de Biologia Aplicada à Agropecuária, FCAV/UNESP. Rodovia Carlos Tonanni, km 5. Jaboticabal/SP. CEP: 14870-000.

${ }^{4}$ Prof. Titular, Departamento de Biologia Aplicada à Agropecuária, FCAV/UNESP, Jaboticabal/SP.

${ }^{5}$ Prof.Adjunto, Departamento de Ciências Exatas, FCAV/UNESP, Jaboticabal/SP.
} 
propanil no controle de plantas daninhas em cultura de arroz irrigado (Almeida \& Rodrigues, 1988).

Segundo Chen (1986) e Liu \& Tsai (1986) o butachlor promove inibição nos teores de clorofila de plantas de arroz, inibindo principalmente a formação dos pigmentos clorofilianos. Randhawa \& Gill (1989) constataram que em algas, o butachlor também provoca considerável decréscimo na quantidade de clorofila. Yogo \& Ishizuka (1986) estudando os efeitos do propanil em arroz, verificaram que este produto provoca inibição da fotossíntese, interferindo na reação de Hill e em muitas outras etapas bioquímicas do processo fotossintético. Hofstra \& Switzer (1968) e Pandy (1985) relataram que o propanil atua nas membranas dos cloroplastos, contribuindo para a fitotoxicidade. Quanto ao herbicida glyphosate, o primeiro sintoma visível de toxicidade nos vegetais, segundo Kitchen et al., (1981), é a presença da clorose que pode ser o resultado da diminuição da síntese ou do aumento da degradação dos pigmentos clorofilianos.

Caracteristicamente, a planta aquática Spirodela punctata (G.F. W. Meyer) Thompson (Lemnaceae) possui acentuada sensibilidade para detectar diversos poluentes nos ambientes aquáticos (Wang, 1984; Landolt \& Kandeler, 1987; Zirschky \& Reed, 1988), tendo já sido reportado na literatura estudos sobre as alterações nos teores de clorofila de espécies de Lemnaceae tratadas com diversos herbicidas (Treichel, 1974a,b; Beaumont et al., 1976; Price \& Wain, 1976; Grenier \& Beaumont, 1983; Mattoo et al., 1983; Wejnar \& Michel, 1983; Wejnar \& Tais, 1983). Porém, para os herbicidas em estudo neste trabalho não foram encontradas quaisquer informações a respeito de efeitos em pigmentos de Spirodela punctata, exceto, relatos de Landolt \& Kandeler (1987) para o

\footnotetext{
${ }^{6}$ Machete ${ }^{\circledR} 60 \%$, Monsanto do Brasil Ltda.

${ }^{7}$ Roundup $® 48 \%$, Monsanto do Brasil Ltda.

${ }^{8}$ Stam F- 4® 48\%, Rohm and Haas Brasil Ltda.
}

herbicida glyphosate, indicando sua toxicidade para espécies de Lemnaceae em geral.

Portanto, o objetivo do presente trabalho foi o de verificar os efeitos de diferentes concentrações dos herbicidas butachlor, glyphosate e propanil nos teores dos pigmentos clorofilianos de $S$. punctata, visando obter um maior conhecimento das respostas biológicas da espécie, como também, propor a utilização destes pigmentos como fator de sensibilidade da planta quando presente em ambientes aquáticos poluídos por estes herbicidas.

\section{MATERIAL E MÉTODOS}

A população original das plantas de $S$. punctata foi coletada em lagoa localizada no bairro do Sobrado, município de Rio Claro, SP. Foi efetuada a limpeza das plantas coletadas na lagoa através de lavagens com água destilada, para a remoção de detritos. Logo após, as plantas foram acondicionadas em bandejas de plástico contendo quatro a seis litros de solução nutritiva de Hutner na proporção de 1:1 (Hutner, 1953), e mantidas em sala climatizada com luminosidade de 5000 lux, fotoperíodo de 12 horas claro e 12 horas escuro e, temperatura constante de $25^{\circ} \pm 1^{\circ} \mathrm{C}$. Somente após um mês de aclimatação, as plantas foram utilizadas nos experimentos.

Foram utilizados herbicidas comumente empregados no controle de plantas aquáticas daninhas, a saber: butachlor ${ }^{6}$ (2 - cloro -2',6' dietil -N-(butoximetil) acetanilida; solubilidade em água $=20 \mathrm{ppm}$ a $20^{\circ} \mathrm{C}$; classe toxicólogca II, medianamente tóxico), glyphosate ${ }^{7} \quad(\mathrm{~N}-$ (fosfonometil)glicina; solubilidade em água $=$ $10000 \mathrm{ppm}$ a $25^{\circ} \mathrm{C}$; classe toxicológica III, pouco tóxico), e propanil ${ }^{8}$ (3,4-dicloropropionanilida; solubilidade na água $=225 \mathrm{ppm}$ a $25^{\circ} \mathrm{C}$; classe toxicológica II, medianamente tóxico), nas concentrações (tratamento) de 0 (controle); 0,005; 0,$05 ; 0,5$ e $5 \mathrm{mgL}^{-1}$. 
A montagem dos ensaios foi realizada utilizando-se de potes de plástico branco opaco, com $13,5 \mathrm{~cm}$ de diâmetro superior, $10,5 \mathrm{~cm}$ de diâmetro inferior e $8 \mathrm{~cm}$ de altura, com $300 \mathrm{ml}$ de solução (solução de Hutner 1:1 mais as respectivas concentrações de herbicidas) e $2 \mathrm{~g}$ (massa fresca em gramas) de Spirodela punctata. Os bioensaios foram conduzidos em sala climatizada por sete dias completos.

Determinaram-se os teores de clorofila pelo método de Arnon (1949). Para tanto, foi utilizado $1 \mathrm{~g}$ de frondes frescas, as quais foram maceradas com $20 \mathrm{ml}$ de acetona $80 \%$ (v/v). O volume foi medido e completado até $15 \mathrm{ml}$ com acetona. Após a centrifugação, o volume do sobrenadante foi medido e anotado (volume final). O resíduo foi descartado. Com o sobrenadante obtido nos vários tratamentos estudados, procederam-se às leituras espectrofotométricas em $\mathrm{A}_{663} \mathrm{~nm}$ (clorofila a) e $\mathrm{A}_{645} \mathrm{~nm}$ (clorofila b) em espectrofotômetro Coleman Perkin-Elmer. Utilizando-se os dados das leituras espectrofotométricas, calculou-se o conteúdo de clorofila $\mathbf{a}$, b e razão clorofila $\mathbf{a} / \mathbf{b}$, através das fórmulas descritas em Arnon (1949). Os teores de clorofila foram expressos em $\mathrm{mg} \mathrm{g}^{-1}$ de massa fresca (M.F.).

A análise estatística foi realizada segundo um delineamento experimental inteiramente casualizado com cinco repetições para cada tratamento. A análise de variância foi efetuada com o teste F, utilizando-se do teste de Tukey para comparações múltiplas (Banzatto \& Kronka, 1992). Para a análise dos efeitos das concentrações dos três herbicidas, efetuaram-se estudos de regressão polinomial.

\section{RESULTADOS E DISCUSSÃO}

Os resultados da análise de variância referente aos quadrados médios (Q.M.) dos teores de clorofila a e b de $S$. punctata, sete dias após a aplicação dos herbicidas, evidenciaram efeitos significativos para testemunha $v s$ fatorial apenas dos teores de clorofila $\mathbf{b}(0,0021 *)$.
A seguir, foi realizado o estudo de regressão polinomial (regressão linear, R.L. e regressão quadrática, R.Q.) para cada produto e, exceto o glyphosate para clorofila $\mathbf{b}$, os herbicidas provocaram respostas significativas $(\mathrm{P}<0,01)$ nos teores de clorofila a e b de Spirodela punctata.

A Figura 1 apresenta o comportamento linear da intensa redução da clorofila a pelas diferentes concentrações de glyphosate e propanil. Os valores encontrados de quadrados médios (Q.M.) para regressão linear (R.L.) foi de $0,0139 * *$ e $0,1464 * *$, respectivamente para o glyphosate e propanil. O butachlor, entretanto, evidenciou um comportamento mais heterogêneo, apresentando significância na regressão quadrática (Q.M.de 0,0174**). Esta tendência de curva mostrou que o herbicida provocou aumento no teor de clorofila a, principalmente, na faixa de concentrações mais baixas $\left(0,5\right.$ a $\left.2,5 \mathrm{mg} \mathrm{L}^{-1}\right) \mathrm{e}$, diminuição acentuada nas concentrações mais elevadas.

Para os teores de clorofila $\mathbf{b}$, visualizado na Figura 2, verifica-se que, apenas o butachlor (Q.M. para R.L. foi de $0,0047^{* *}$ ) e propanil (Q.M. para R.L. foi de $0,1126^{* *}$ ) causaram intensa redução no pigmento clorofiliano. $\mathrm{O}$ comportamento linear das concentrações do butachlor e propanil mostra uma redução do pigmento com o aumento das concentrações.

De fato, em algas, Pandy (1985) verificou que diferentes concentrações de propanil inibia a síntese de clorofila a, induzindo à uma perda de outros pigmentos fotossintéticos. Estudos anteriores de Hofstra \& Switzer (1968), evidenciaram que este herbicida atuava nas membranas dos cloroplastos.

Fisichella et al. (1984) relataram que, em folhas de espécies arbóreas, a medida que se aumentava a concentração de glyphosate ocorria significativa redução dos teores de clorofila $\mathbf{a}$ e $\mathbf{b}$. O comportamento do glyphosate provocando diminuição linear do conteúdo de clorofila a em $S$. punctata, é uma provável evidência de que a entrada do produto na planta foi satisfatória e, sua ação foi principalmente sobre este pigmento (Figura 1), uma vez que não provocou quaisquer 
alterações significativas nos teores de clorofila $\mathbf{b}$. Kitchen et al. (1981) reportaram o efeito detrimental do glyphosate sobre a síntese de ALA (ácido d-aminolevulínico), um percursor da biossíntese da clorofila. Campbell et al. (1976) e Pihakaski \& Pihakaski (1980) constataram que, o glyphosate danificava a ultraestrutura dos cloroplastos. Cowgill et al. (1989) observaram que, em espécies de Lemna tratadas com outro produto, tryclopyr, apresentavam redução significativa da clorofila a, após sete dias de experimentação, enquanto que os efeitos negativos sobre a clorofila b somente ocorriam após 14 dias. Como as condições metodológicas deste trabalho foram de sete dias, provavelmente, este intervalo de tempo tenha sido insuficiente para a ação do glyphosate na planta como ocorreu com o triclopyr em espécies de Lemna.

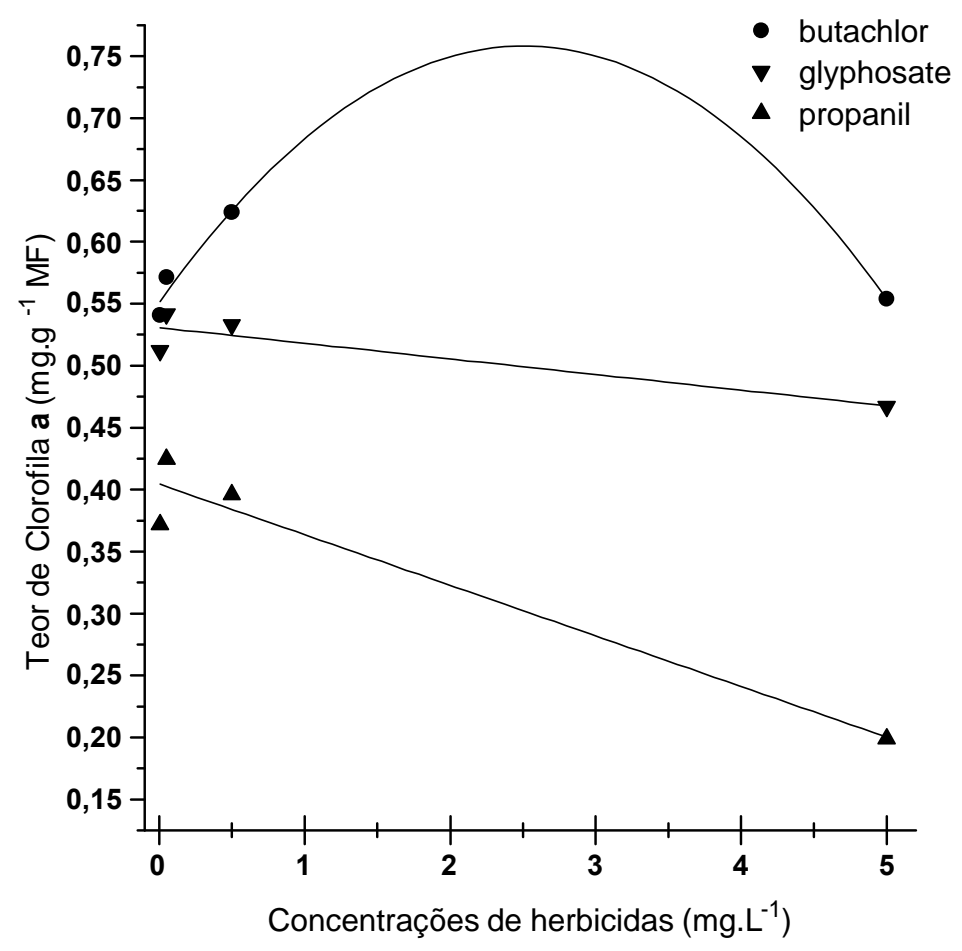

FIGURA 1. Teor de clorofila a de Spirodela punctata sob efeito dos herbicidas butachlor, glyphosate e propanil.

butachlor: $\mathrm{y}=0,55119+0,16495 \mathrm{x}-0,03288 \mathrm{x}^{2}$ e $\mathrm{R}^{2}=0,9298$.

glyphosate: $\mathrm{y}=0,53076-0,01261 \mathrm{x}$ e $\mathrm{R}^{2}=0,8357$.

propanil: $\mathrm{y}=0,40443-0,04085 \mathrm{x}$ e $\mathrm{R}^{2}=0,9451$.

Lockchart et al. (1989), entretanto, relataram que o glyphosate é tóxico para espécies de Lemnaceae, mas, salientaram que as plantas são relativamente insensíveis ao herbicida quando diluído em água, provavelmente por causa da menor disponibilidade do produto para a planta.
Wejnar et al. (1992) observaram que, baixas concentrações de herbicidas na água, não causam alterações nos teores de clorofila de Lemna gibba. Mas, Wejnar \& Tais (1983) já haviam verificado que a concentração de $0,1 \mathrm{mg} \mathrm{L}^{-1}$ do herbicida nitrofen, em solução nutritiva, diminuia os teores 
de clorofila a e b de L. gibba. De um modo geral, Good (1961) relatou que a clorose (diminuição acentuada de clorofila) de folhas tratadas com herbicidas, ocorre devido a destruição da membrana dos cloroplastos e, posterior inibição da reação de Hill na fase luminosa da fotossíntese.

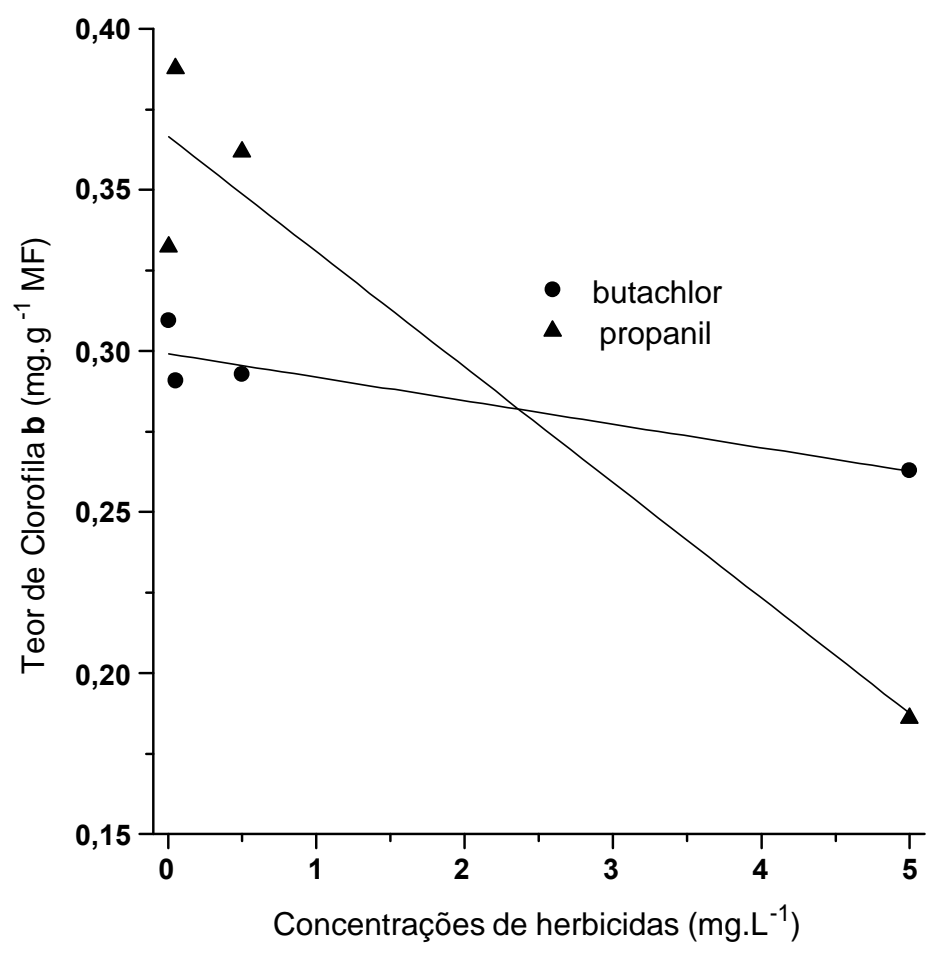

FIGURA 2. Teor de clorofila b de Spirodela punctata sob efeito dos herbicidas butachlor e propanil. butachlor: $\mathrm{y}=0,29913-0,00729 \mathrm{x}$ e $\mathrm{R}^{2}=0,8405$. propanil: $\mathrm{y}=0,36666-0,03583 \mathrm{x}$ e $\mathrm{R}^{2}=0,9235$.

De acordo com Randhawa \& Gill (1989) o herbicida butachlor inibe a formação dos pigmentos clorofilianos em culturas de arroz e, também, causa diminuição na quantidade de clorofila em algas. Porém, na Figura 1 observa-se uma tendência de aumento da clorofila a pelas diferentes concentrações deste herbicida. Provavelmente, este resultado esteja relacionado com a absorção celular de nutrientes, pois, com o herbicida atrazine, Simard et al. (1991) relataram que, o atrazine provocava significativo aumento de clorofila em outra espécie de Lemnaceae, Lemna minor, em decorrência do aumento da absorção celular do cálcio e magnésio e/ou pelo favorecimento de uma maior fixação destes elementos nas membranas dos cloroplastos.

A análise de variância e o teste de Tukey (Tabela 1) efetuados para a razão clorofila $\mathbf{a} / \mathbf{b}$ de S. punctata mostrou que, independentemente das concentrações usadas, glyphosate e propanil provocaram acentuadas alterações. O efeito do propanil foi extremamente drástico na diminuição da razão clorofila $\mathbf{a} / \mathbf{b}$, apresentando os menores valores dentre os três herbicidas. Também, o herbicida glyphosate causou um decréscimo nos pigmentos clorofilianos, porém, somente nas concentrações mais elevadas $\left(0,5\right.$ e $\left.5,0 \mathrm{mg} \mathrm{L}^{-1}\right)$. Com relação ao butachlor não foi constatada 
quaisquer alterações na razão clorofila $\mathbf{a} / \mathbf{b}$. Salienta-se que, a redução da razão clorofila $\mathbf{a} / \mathbf{b}$ é uma indicação de que as folhas estão em processo de envelhecimento (Wolf, 1956; Goodwin, 1958).
Assim, a drástica diminuição da razão clorofila $\mathbf{a} / \mathbf{b}$ pelo propanil e glyphosate podem indicar que estes herbicidas tenham intensificado a senescência nas frondes de S. punctata.

TABELA 1. Análise de variância e resultados do teste de Tukey referente à razão clorofila $\mathbf{a} / \mathbf{b}$ de Spirodela punctata, sete dias após a aplicação de herbicidas.

\begin{tabular}{|c|c|c|c|}
\hline \multirow{2}{*}{ Causa da Variação } & \multirow{2}{*}{ G.L. } & \multicolumn{2}{|c|}{ Quadrados Médios } \\
\hline & & \multicolumn{2}{|c|}{ Razão Clorofila a/b } \\
\hline Testemunha $v s$ Fatorial & 1 & & $0,0797^{\mathrm{ns}}$ \\
\hline Concentrações (C) & 3 & & $0,0420^{\mathrm{ns}}$ \\
\hline Herbicidas d. $0,005 \mathrm{mg} \mathrm{L}^{-1}$ & 2 & & $0,9928 * *$ \\
\hline Herbicidas d. $0,05 \mathrm{mg} \mathrm{L}^{-1}$ & 2 & & $1,5306^{* *}$ \\
\hline Herbicidas d. $0,5 \quad \mathrm{mg} \mathrm{L}^{-1}$ & 2 & & $1,5128 * *$ \\
\hline Herbicidas d. 5,0 $\mathrm{mg} \mathrm{L}^{-1}$ & 2 & & $1,3945^{* *}$ \\
\hline Resíduo & 52 & & 0,0213 \\
\hline \multirow{2}{*}{$\begin{array}{l}\text { Concentrações } \\
\left(\mathrm{mg} \mathrm{L}^{-1}\right)\end{array}$} & \multicolumn{3}{|c|}{ Herbicidas } \\
\hline & butachlor & glyphosate & propanil \\
\hline 0,005 & $1,7528 \mathrm{a}$ & 1,9724 a & $1,1146 \mathrm{~b}$ \\
\hline 0,05 & $1,9710 \mathrm{a}$ & $2,1282 \mathrm{a}$ & $1,1010 \mathrm{~b}$ \\
\hline 0,5 & $2,1378 \mathrm{a}$ & $1,9124 \mathrm{~b}$ & $1,0926 \mathrm{c}$ \\
\hline 5,0 & $2,1174 \mathrm{a}$ & $1,8248 \mathrm{~b}$ & $1,0922 \mathrm{c}$ \\
\hline
\end{tabular}

ns: não significativo $(\mathrm{P}>0,05)$

$* *$ : significativo $(\mathrm{P}<0,01)$

Para cada concentração médias de herbicidas seguidas de mesma letra não diferem entre si pelo teste de Tukey $(\mathrm{P}>0,05)$.

\section{LITERATURA CITADA}

ALMEIDA, F.S., RODRIGUES, B.N. Guia de herbicidas. 2. ed., Londrina, Brasil. 1988. p. 131-136, 324-330, 445-450.

ANDERSON, I.C., ROBERTSON, D. Role of carotenoids in protecting chlorophyll from photoreduction. Plant Physiol., v.35, p.531534. 1960.

ARNON, D.I. Cooper enzymes in isolated chloroplast polyphenoloxidase in Beta vulgaris. Plant Physiol., v.24, n.1, p.1-15. 1949.

BANZATTO, D.A., KRONKA, S.N. Exp. agríc. 2ed. Jaboticabal:FUNEP, 1992. 247 p.

BEAUMONT, G., BASTIN, R., THERRIEN, H.P. Effets physiologiques de l'atrazine à doses sublétales sur Lemna minor L. 1. Influence sur la croissance, la teneur en chlorophylle, en proteíne et en azote soluble et total. Nat. Can., v.103, p.527-533. 1976. 
CAMPBELL, W.F., EVANS, J.O., REED, S.C. Effects of glyphosate on chloroplast ultrastructure of quackgrass mesophyll cells. Weed Sci., n.24, p.22-25. 1976.

CHEN, P.C. Effects of herbicides on growth and photosynthesis of Anabaena $\mathrm{CH}_{2}$ e $\mathrm{CH}_{3}$. Proceedings of The National Science Council Republic of China, B. Life Sciences, v.10, n.3, p.151-156. 1986.

COWGILL, U.M., MILAZZO, D.P., LANDENBERGER, B.D. A comparison of the effect of triclopyr triethylamine salt on two species of duckweed (Lemna) examined for a 7 and 14 day test period. Water Res., v.23, p.617-623. 1989.

FISICHELLA, G., TROPEA, M., SAMBUCO, G. L'influenza del glifosato sul contenuto di clorofilla e di amminoacidi nelle foglie di alcune specie arboree. Nota II. Tecnica Agricola., v.36, n.4, p.335-342. 1984.

GOOD, N.E. Inhibitors of the Hill reaction. Plant Physiol., v.36, n.6, p.788-803. 1961.

GOODWIN, T.W. The changes in carotenoid and chlorophyll pigments in the leaves of deciduous trees during autumn necrosis. Biochem. J., v.68, n.3, p.503-511. 1958.

GRENIER, G., BEAUMONT, G. Effets physiologiques de l'atrazine á doses sublétales sur Lemna minor. 7. Incorporation d'ácetate-1,2- $\left({ }^{14} \mathrm{C}\right)$ dans les groupes de lipide et leurs acids gras. Physiol. Plant., v.57, p.477-484. 1983.

HOFSTRA, G., SWITZER, C.M. The phytotoxicity to propanil. Weed Sci., v.16, p.23-28. 1968.

HUTNER, S.H. Comparative physiology of heterotrophic growth. In: LOOMIS, W.E. (ed.), Growth and differentiation in plants. Iowa State Coll. Press. 1953. p.417446.

KITCHEN, L.M., WITT, W.W., RIECK, C.E. Inhibition of chlorophyll accumulation by glyphosate. Weed Sci., v.29, n.4, p.513516. 1981.

LANDOLT, E., KANDELER, R. The family of Lemnaceae - a monographic study: phytochemistry, physiology, application, bibliography. Biosystematic investigation the family of duckweeds. Veroffenteichungendes Geobotanischen Institutes der Eidg. Techn. Hochschule, (ETH). 1987. v.4, n.95, 638 p.

LIU, A., TSAI, W.F. Effect of butachlor on rice and some paddy weeds. J. of the Agric. Assoc. of China, n.135, p.1-9. 1986.

LOCKHART, W.L., BILLECK, B.N., BARON, C.L. Bioassays with a floating aquatic plant (Lemna minor) for effects of sprayed and dissolved glyphosate. Hidrobiol., n.188/189, p.353-359. 1989.

MATTOO, A.K., WERGIN, W.P., ST. JOHN, J.B. Adaptative reorganization of thylakoid components of Spirodela oligorrhiza cultured on sublethal doses of atrazine. Plant Physiol., v.72, p.56, 1983. (Suplemento).

PANDY, A.K. Effects of propanil on growth and cell constituents of Nostoc calcicola. Pestic. Biochem. and Physiol., v.23, n.2, p.157-162. 1985.

PIHAKASKI, S., PIHAKASKI, K. Effects of glyphosate on ultrastructure and photosynthesis of Pellia epiphylla. Ann. Bot., v.46, p.133-141. 1980.

PRICE, D.N., WAIN, R.L. Studies on plant growth-regulating substances. XLI. 
Structure-activity relationships and metabolism of a group of nitrophenols capable of inhibiting chloroplast development. Ann. Appl. Biol., v.83, p.115-124. 1976.

RANDHAWA, S.K., GILL, H.S. Influence of herbicides applied in transplanted rice on chlorophyll and carotenoids in wheat leafs. J. Res., v.26, n.1, p.29-30. 1989.

SANDMANN, G., BOGER, P. Herbicides affecting plant pigments. British Crop Protection Conference Weeds. Proceedings ...., v.1, p.139-148. 1987.

SIMARD, S., PROTEAU, L., BEAUMONT, G., GRENIER, G. Increase of chloroplast granum stability, indiced by sublethal concentrations of atrazine, in Lemna minor fronds grown on a medium partially deficient in calcium or magnesium. Plant Physiol. Biochem.,v.29, p. 631-638. 1991.

TREICHEL, S. Einfluss von morphaktinen auf den stoffwechsel hoherer pflanzen. I. die wirkung auf die atmung und auf einige glykollytische enzyme. Biochem. Physiol. Pflanzen., v.166, p.481-493. 1974a.

TREICHEL, S. Einfluss von morphaktinen auf den stoffwechsel hoherer pflanzen. II. die wirkung auf die photosynthese und den gehalt an starke, ATP aun chlorophyll. Biochem. Physiol. Pflanzen., v.116, p.495509. 1974b.

WANG, W. Uses of aquatic plants in ecotoxicology. Environ. Internat., v.10, p. i-iii, 1984. (Editorial).
WEJNAR, R., HAUSDORFER, R., SCHMIDT, M., WEISSENBORN, F. Investigations on photosynthetic pigments of Lemnaceae. 13. Comparative analysis of the bleaching effect of the herbicides amitrole, diuron and paraquat, with special consideration of NOEC. Angew. Bot., v.66, p.5-6. 1992.

WEJNAR, R., MICHEL, D. Untersuchungen zum einfluss des nitrofens auf die chloroplastenstruktur von Lemna gibba $\mathrm{L}$. Beitr. Biol. Pflanzen.,v.58, p.435-441. 1983.

WEJNAR, R., TAIS, S. Untersuchungen zum einfluss des nitrofens auf wachstum und pigmentgehalt von Lemna gibba L. Beitr. Biol. Pflanzen., v.58, p.427-434. 1983.

WOLF, F.T. Changes in chlorophyll $\underline{\mathrm{a}}$ and $\underline{\mathrm{b}}$ in autumn leaves. Am. J. Bot., v.43, p.714718. 1956.

WOLF, F.T. Effects of chemical agents in inhibition of chlorophyll synthesis and chloroplast development in higher plants. Bot. Ver., v.43, p.395-425. 1977.

YOGO, Y., ISHIZUKA, K. Tolerance of finger millet to propanil. 3. Relationship between propanil binding by chloroplast and inhibition of photosynthetic eletron transport. Weed Res., v.31, n.2, p.152-156. 1986.

ZIRSCHKY, J., REED, S.C. The use of duckweed for wastewater treatment. J. Water Poll. Control Fed., v.60, n.7, p.1253-1258, 1988. 